\title{
Health Insurance
}

\section{Will Choice-Based Reform Work for Medicare? Evidence from the Federal Employees Health Benefits Program}

\author{
Curtis S. Florence, Adam Atherly, and Kenneth E. Thorpe
}

Objective. To examine the effect of premiums and benefits on the health plan choices of older enrollees who choose Federal Employees Health Benefits Program (FEHBP) health plans as their primary payer.

Data Sources. Administrative enrollment data from the Office of Personnel Management $(\mathrm{OPM})$ and plan premiums and benefits data taken from the Checkbook Guide to health plans.

Study Design. We estimate individual plan choice models where the choice of health plan is a function of out-of-pocket premium, actuarial value, plan attributes, and individual characteristics. Plan attributes include plan structure (fee-for-service/preferred provider organization, point-of-service, or health maintenance organization), drug benefit structure, and whether or not the plan covers other types of spending such as dental services and diabetic supplies. The models are estimated by conditional logit. Our study focuses on three populations that currently choose FEHBP as their primary health care coverage and are similar to the Medicare population: current employees and retirees who are approaching the age of Medicare eligibility (ages 60-64) and current federal employees age $65+$. Current employees age $65+$ are eligible for Medicare, but their FEHBP plan is their primary payer. Retirees and employees 60-64 are not yet eligible for Medicare but are similar in many respects to recently age-eligible Medicare beneficiaries. We also estimate our model for current employees age 55 and younger as a comparison group.

Data Collection Methods. We select a random sample of retirees and employees age $60-64$, as well as all current employees age $65+$, from the OPM administrative database for the calendar year 2001. The plan choices available to each person are determined by the plans participating in their metropolitan statistical area. We match plan premium and attribute information from the Checkbook Guide to each plan in the enrollee's list of choices.

Principal Findings. We find that current workers 65+, 60-64, and non-Medicare eligible retirees are sensitive to variation in plan premiums. The premium elasticities for these groups are similar in magnitude to those of the age 55 and under employee group. Older workers and retirees not yet eligible for Medicare are willing to pay a substantial amount for plans with open provider networks. The willingness to pay for open networks is significantly greater for these groups than for younger employees. Willingness 
to pay for open network plans varies significantly by income, but varies little by age within group.

Conclusions. Our finding that older workers and non-Medicare eligible retirees are sensitive to plan premiums suggests that choice-based reform of Medicare would lead to cost-conscious choices by Medicare beneficiaries. However, our finding that these groups are willing to pay more for open network plans than younger employees suggest that higher risk individuals may migrate toward higher benefit, higher cost plans. Our findings on the relationship between income and willingness to pay for open network plans suggest that means testing is a viable reform for lowering Medicare program costs.

Key Words. Medicare, health insurance, health plan choice

Over the past several decades, the Medicare program has experimented with providing Medicare beneficiaries health plan choices through its managed care program. As a result of the Medicare Prescription Drug, Improvement and Modernization Act (MMA) of 2003, the health plan choices available to Medicare beneficiaries expand dramatically. Beginning in 2006, Medicare enrollees are allowed to choose from regional preferred provider organizations (PPO), in addition to the more established health maintenance organization (HMO) plans and traditional fee-for-service (FFS) Medicare. These plans will not be Medicare supplemental plans, but will be the primary payer for all Medicare covered services. Medicare beneficiaries will also be allowed to choose among competing prescription drug plans. In addition to increased plan choices, the MMA has also introduced means testing into Medicare by increasing premiums for Medicare part B (physician services) for the highest income beneficiaries and by allowing low-income beneficiaries to enroll in prescription drug plans at reduced or zero premiums (O'Sullivan et al. 2004).

As the name of the MMA implies, the stated purpose of this legislation is to improve the benefits offered to Medicare beneficiaries while simultaneously attempting to control costs by introducing plan competition and cost-conscious decision making by consumers into the system. One of the major models for this legislation was the Federal Employees Health Benefits Program (FEHBP), which provides health benefits for almost nine million federal employees, retirees, and their dependents. FEHBP is often held up a

Address correspondence to Curtis S. Florence, Ph.D., Assistant Professor, Department of Health Policy and Management, Rollins School of Public Health, Emory University, 1518 Clifton Road NE, Atlanta, GA 30322. Adam Atherly, Ph.D., Assistant Professor, and Kenneth E. Thorpe, Ph.D., Robert W. Woodruff Professor and Chair, are with the Department of Health Policy and Management, Rollins School of Public Health, Emory University, Atlanta, GA. 
"successful" federal health care program, which has managed to modernize its benefit structure while moderating premium increases (Butler and Moffit 1995). In fact, the original House version of the MMA explicitly called for "FEHBP-style reform" in Medicare starting in 2010 (HR1 2003).

Similar to what is envisioned for the Medicare program, FEHBP enrollees have a choice of several relatively open-network PPO plans that have premiums which are experienced rated nationally over their FEHBP enrollment. Depending on location of residence, enrollees also have a choice of several traditional closed-network HMO plans, and a smaller number of point-of-service (POS) plans, which share many features of HMOs but will pay for care outside of the plan's network. The federal government pays 75 percent of the plan premium up to a predetermined cap, thereby requiring enrollees to pay more out-of-pocket for higher premium plans.

While the FEHBP is mentioned as a model for Medicare reform, there is no empirical evidence that shows how out-of-pocket premiums and plan benefits affect the choice of health plans for the Medicare population in the FEHBP. In order for such a "choice based" reform to succeed, a necessary condition is that consumers are responsive to premiums and benefits in making their plan selection. The purpose of this study is to examine how differences in out-of-pocket premiums and benefits influence plan choice among older enrollees in the FEHBP. Although there is a large body of research examining health plan choice among the nonelderly, very little is known about the applicability of these results to the elderly.

The specific questions we address in this study are

- How sensitive are enrollees to differences in plan premiums?

- How much are consumers willing to pay for open provider networks?

- How much are consumers willing to pay for plan benefits?

- How are plan choices affected by consumer income?

- Do older enrollees make these choices differently than younger enrollees?

These questions are important because the changes to Medicare increase the number of plan choices to enrollees, but also require enrollees to pay greater premiums for greater benefits, choose among open-network and closed-network plans, and ties out-of-pocket premium payments to enrollee income. How consumers react to such choices is vitally important to understanding the impact of these reforms. 
Our hypotheses in this study are straightforward; first, we expect that choice of plan will be negatively related to the out-of-pocket premium. Second, holding premiums constant, plan choice will be positively associated with greater plan benefits. Third, older persons will be less likely to choose managed care plans, because plans with more open provider networks will provide more freedom to continue seeing providers with whom they have established relationships. Finally, we expect willingness to pay for plan benefits to vary with income. If plan benefits are a normal economic good, higher income persons will be willing to pay more for better benefits.

\section{PREVIOUS RESEARCH}

Several previous studies have examined health plan choice for the Medicare population. ${ }^{1}$ Buchmueller (2000) used data from the University of California retiree health benefits program to examine the effect of premium variations on the probability of switching health plans and to estimate the price elasticity of demand for FFS versus managed care. The price elasticity of demand for FFS versus managed care was estimated to be -0.16 . Buchmueller's study is somewhat limited in its generalizability because of the uniform benefit structure faced by retirees and because the University of California used a fixed dollar contribution. Atherly, Dowd, and Feldman (2004) examined health plan choice among Medicare beneficiaries and reported an out-of-pocket premium elasticity of -0.134 . Feldman et al. (1993), using data on the supplemental health plan choices of Medicare beneficiaries in the Minneapolis/ St. Paul area found a price elasticity of health plan choice of approximately - 2. Dowd, Feldman, and Coulam (2003) examined the factors affecting choice within the Medicare + Choice $(M+C)$ sector and found that a $\$ 10$ increase in the out-of-pocket premium would result in a loss of four percentage points of $\mathrm{M}+\mathrm{C}$ market share (e.g., from 25 to 21 percent). Among benefits, both Atherly, Dowd, and Feldman (2004) and Dowd, Feldman, and Coulam (2003) found that generous prescription drug benefits (with a cap above a threshold) were significant predictors of market share.

There have also been a series of studies examining plan choice in the nonelderly. Royalty and Solomon (1999) estimated premium elasticities for employees in the Stanford University health benefits and found out-of-pocket elasticities ranging from -0.2 to -0.6 . Cutler and Reber (1998) used a change in the plan offerings for Harvard University as a "natural experiment" and estimated an out-of-pocket premium elasticity -0.3 in year 1 and -0.6 
in year 2. Feldman et al. (1989), using data from large Minneapolis employers, reported an elasticity of -2.0 . Finally, Florence and Thorpe (2003) used the FEHBP to examine the health plan choices of active federal employees who are not Medicare eligible. They estimated a price elasticity of demand for outof-pocket premiums of -2.0. In addition, this study found that, controlling for premiums and plan benefits, enrollees were much more likely to choose a FFS plan, and this likelihood increases with the enrollee's age.

Although Florence and Thorpe (2003) found that federal employees are sensitive to price when choosing health plans, this price sensitivity declines with age. For example, the price elasticity of federal employees ages 18-29 is 1.35 times greater than the price elasticity of employees ages 60-64. Buchmeuller (2000) and Royalty and Solomon (1999) also found that premium elasticity declined with age. However, Atherly, Florence, and Thorpe (2005) report that premium elasticities do not decline with age, but rather increased costs associated with switching plans for older persons reduces the probability of changing plans.

While the previous research cited has revealed a wealth of information about the price sensitivity of consumers in managed competition systems, and about price sensitivity in the FEHBP, there are several gaps in the literature that are addressed in this study. Previous studies of retiree health choice are either based on single markets where managed care is very prevalent and health care costs and plan premiums are relatively low (Buchmeuller [2003] in California and Feldman et al. [1993] in Minnesota) or on the current M+C plans (Atherly et al. [2004] and Dowd et al. [2003]). The University of California only offers five managed care plans, all of which are relatively similar in benefit structure. The other studies used $\mathrm{M}+\mathrm{C}$ data, but under the current structure of the $\mathrm{M}+\mathrm{C}$ program, there is limited benefit variation. For example, in the Dowd et al. (2003) study, 75 percent of plans had premiums equal to the lowest premium offered in the market. In contrast, many of the proposed reforms of the Medicare system envision substantial variation in benefits and premiums, as is found in the FEHBP.

In addition, FEHBP has a large number of competing open network plans, similar to what some reformers envision for Medicare. With Buchmueller, the only open network plan had very low enrollment and was experiencing an adverse selection "death spiral." Plans based on the current Medicare structure necessarily have a single open network option-traditional FFS-with no gatekeeper or restrictions on access to specialists. The FEHBP had 11 open-network PPO options in 2001 with no gatekeeper requirement or restrictions on access to specialists, and the two most popular 
comprise the majority of enrollment in the system. In addition, several local point of service (POS) plans operate in the system, and have flexibility in choice of provider that is similar to the PPO plans. Therefore, we are able to

examine health plan choices in a system where open network plans ${ }^{2}$ are a viable option for enrollees.

\section{CONCEPTUAL FRAMEWORK AND EMPIRICAL MODEL}

Individuals are assumed to select the FEHBP health plan that maximizes their expected utility. Suppose that the enrollee has a choice of $Y=\left(y_{1}, \ldots, y_{j}\right)$ health plans. The utility that the enrollee receives from plan $j$ is a function of the attributes of the plan $X_{j}$, which includes the plan's out-of-pocket premium and benefits, and the enrollee's individual attributes $Z_{i}$, which include variables such as the consumer's income and health status. The enrollee will then choose the health plan that produces the highest level of utility, which is determined by plan and enrollee attributes.

This type of utility maximization problem can be estimated empirically using the random utility framework. Formally,

$$
U(\text { choice } j \text { for individual } i)=X_{i j} \beta+\varepsilon_{i j}
$$

where $U(\cdot)$ is the level of utility from choice $j$, $J$ is the number of health plans available to the individual in the market, $X_{i j}$ represents characteristics of the health plans, such as the out-of-pocket premium and expected benefits, and characteristics of the individual such as age and income. $\varepsilon_{i j}$ is a random residual. The individual chooses the alternative $j$ that produces the highest level of utility. In the random utility framework, if the individual-specific effect $\varepsilon_{i j}$ is independently distributed with an extreme value distribution across the choices, the probability an individual $i$ chooses alternative $j$ is

$$
\operatorname{Prob}\left[y_{i}=j\right]=\exp \left(X_{i j} \beta\right) / \Sigma_{\forall j} \exp \left(X_{i j} \beta\right)
$$

where $y_{i}$ is the index of the choice made. The number of options $j$ available to a particular individual varies depending on the number of managed care plans offered in the individual's market.

Our specification for the deterministic part of the utility function is

$$
\begin{aligned}
X_{i j} \beta= & \alpha_{1} \mathrm{OPP}_{j}+\alpha_{2} \mathrm{PPO}_{j}+\alpha_{3} \mathrm{POS}_{j}+\alpha_{4} \mathrm{AV}_{j}+\mathrm{OB}_{j} \theta+\gamma_{1}\left(\mathrm{PPO}_{j} \times \text { age }\right) \\
& +\gamma_{2}\left(\mathrm{PPO}_{j} \times \text { income }\right)+\gamma_{3}\left(\mathrm{POS}_{j} \times \text { age }\right)+\gamma_{4}\left(\mathrm{POS}_{j} \times \text { income }\right)
\end{aligned}
$$


where $\mathrm{OPP}_{j}$ is the annual out-of-pocket premium for plan $j, \mathrm{PPO}_{j}=1$, if the plan is one of the national preferred provider organization plans, $\operatorname{POS}_{j}=1$, if the plan is one of the local POS plans, $\mathrm{AV}_{j}$ the actuarial value of plan $j$, defined as the percent of expected health care spending covered by the plan for an "average" FEHBP beneficiary, $\mathrm{OB}_{j}$ the composition of benefits of plan $j$, including drug, dental, and other types of coverage, income the annual income from federal employment or retirement, and age the enrollee's age in years.

The term $\alpha_{1}$ measures the effect of out-of-pocket premium on the likelihood of plan selection, while $\alpha_{2}$ and $\alpha_{3}$ measure the effect of the preference for the national PPO plans and local POS plans, respectively, holding plan premiums and benefits constant. $\alpha_{4}$ measures the effect of plan benefits in terms of the percent of expected spending covered and $\theta$ the effect of the composition of benefits on the likelihood the plan is selected. Interactions of the plan attributes and personal characteristics are included to account for the fact that the attributes may have different effects on plan selection for different types of employees. The terms $\gamma_{1}$ and $\gamma_{3}$ can be interpreted as measures of "risk segmentation" - that is, older (higher risk) individuals are more likely to choose higher benefit plans, all else being equal. The terms $\gamma_{2}$ and $\gamma_{4}$ measure the change in preference for PPO and POS plans at different levels of income. This variation by income will allow us to measure the impact of means testing on plan choices.

In the nonlinear logit specification, the coefficients are not directly comparable across different populations. It is not possible to test for differences in the magnitude of logit coefficients for different populations because the coefficients are scaled by the variance of the error for the population used for the estimation. In our study, we will be comparing estimates across four different types of enrollees that vary substantially by average health status. These differences in health status could lead to different a different level of variance across the populations. For that reason, it will be necessary to transform the coefficients into measures that have an economic interpretation that can be compared across the different groups of FEHBP enrollees. We will use two different measures of the magnitude of the effect of plan attributes on plan choice. For the effect of out-of-pocket premiums, we will calculate the premium elasticity. Our premium elasticity measure from this model is defined as

$$
E_{D}=\mathrm{OPP}_{j} \times \alpha_{1} \times[1-P(\text { choice } j)]
$$

holding the premiums of all other plans in the choice set constant. For the effect of other plan attributes on plan choice, we will use a measure of willingness to pay. The measure of willingness to pay is based on the random 
utility theory that is the basis for the conditional logit model. Willingness to pay asks "how much must the consumer pay for a change in plan attributes to leave overall utility constant?" This measure may be found by taking the total derivative of the utility function ${ }^{3}$

$$
\begin{aligned}
d U= & \alpha_{1} d \mathrm{OPP}_{j}+\alpha_{2} d \mathrm{PPO}_{j}+\alpha_{3} d \mathrm{POS}_{j}+\alpha_{4} d \mathrm{AV}_{j}+d \mathrm{OB}_{j} \theta+\gamma_{1}\left(d \mathrm{PPO}_{j} \times \text { age }\right) \\
& +\gamma_{2}\left(d \mathrm{PPO}_{j} \times \text { income }\right)+\gamma_{3}\left(d \mathrm{POS}_{j} \times \text { age }\right)+\gamma_{4}\left(d \mathrm{POS}_{j} \times \text { income }\right)
\end{aligned}
$$

and setting $d U=0$. Then, for example, the willingness to pay for an increase in plan actuarial value is given by $0=\alpha_{1} d \mathrm{OPP}+\alpha_{4} d \mathrm{AV}=>d \mathrm{OPP} / d \mathrm{AV}=$ $-\alpha_{4} / \alpha_{1}$. So, the measure of willingness to pay can be easily constructed using the ratio of the regression coefficients (Train 2003). This measure has appeal because of its straightforward economic interpretation and because it allows us to compare the magnitude of plan characteristics on plan choice across different populations of enrollees. As the willingness to pay measure uses the ratio of the coefficients, the variance scale factor cancels out, and direct comparisons can be made across different groups. Standard errors for the willingness to pay measures can be calculated by the "delta method" using the "nlpred" command in STATA version 8.2.

\section{DATA SOURCES}

The data we use in our analysis come from several sources. First, we use administrative data compiled by the Office of Personnel Management (OPM) on the health plan choices of all nonpostal federal employees and retirees for 2001. This file records the health plan that each federal employee and retirees selects, and if the enrollee chooses self-only or family coverage. In addition to health plan choice, the OPM file also records the employee's age, place of residence (by county, metropolitan statistical area, and state), and income from federal employment or retirement.

We collected data on FEHBP premiums via OPM's website (www.opm. gov). We collected data on plan benefits from the Checkbook Guide, an independent publication that provides information about the different health plans in the FEHBP to assist government employees in choosing a health plan during the annual open enrollment. Finally, we collected detailed information on prescription drug copayments, coinsurance rates and deductibles from the plan brochures on the OPM website.

Our target population is FEHBP enrollees, who are "similar" to age eligible Medicare beneficiaries and are facing premium differences for their 
primary insurance coverage. The most obvious choice for a study sample would seem to be the current Medicare beneficiaries in the program, who are similar in age. However, for Medicare enrollees in the FEHBP, Medicare is the primary payer for Medicare covered services, so the FEHBP plan serves as a Medicare supplement. Further, Medicare eligible enrollees in FEHBP must choose what level of Medicare to enroll in as well as an FEHBP plan. The coverage of each FEHBP plan differs by type of Medicare enrollment, with each plan brochure providing a page that shows the enrollee's primary payer based on Medicare enrollment choice. The Checkbook Guide also offers a detailed breakdown of the advantages and disadvantages of enrolling in part $B$ coverage, and gives expected costs projections for retirees with part A, parts A and $\mathrm{B}$, and no Medicare. The author of the Checkbook Guide generally recommends that enrollees forgo part $\mathrm{B}$. This is not the type of plan choice that is part of the MMA, nor that envisioned by other market oriented reforms to Medicare, so current FEHBP Medicare beneficiaries are not an appropriate population for our study.

Instead, we focus on the FEHBP enrollees who are most similar to Medicare retirees but not actually enrolled in Medicare. Our research will be conducted using three different populations: Medicare eligible full time workers (active workers age 65 and older), retirees and employees age 60-64. Each of these populations has advantages and disadvantages. Workers who are aged 65 and older are eligible for Medicare, but receive their primary insurance coverage through FEHBP; these workers face the right choice set and are the right age. However, that these individuals are still working past the typical retirement age suggests that they are a self-selected group that could be healthier than the typical Medicare beneficiary. The retirees under age 65 face a similar choice set to that envisioned for Medicare reform, and, like most aged Medicare enrollees, are not working, but are younger than the Medicare eligibility threshold. Similarly, workers aged 60-64 have the right choice set, but are also younger than the Medicare eligibility threshold and are not retired. We examine these groups separately because both age and employment are strong proxies for health status.

To understand the relationship of age and employment to health status, and therefore our three samples, we examined differences in health status of workers aged 65 and older, workers 60-64, and retirees 60-64 using the 2001 Medical Expenditure Panel Survey (MEPS). This survey contains information on self-reported health status and the number of health conditions. We compared each category of persons with Medicare beneficiaries age 65-70. We found that workers 65 and older had the best self-reported health (only 8.5 
percent reporting fair or poor health), followed by current workers 60-64 (10.7 percent reporting fair or poor health). In comparison, 14.1 percent of retirees age 60-64 report fair or poor health, as do 21.9 percent of Medicare beneficiaries 65-70. Similar patterns were found for the number of reported health conditions: 3.6 for workers 65 and older, 3.2 for workers 60-64, 4.0 for retirees 60-64, and 4.3 for Medicare beneficiaries age 65-70. Therefore, current retirees age 60-64 appear to be most similar to recently eligible Medicare beneficiaries, followed by current employees 60-64, while current workers 65 and older are the least comparable with current Medicare beneficiaries.

While none of these groups are directly comparable with current Medicare retirees, they are more similar to Medicare retirees than the general population of private health plans that have comprised the bulk of previously published research. To show this, we calculated self reported health status and number of health conditions for workers in private plans age 55 and under. Only 5.7 percent reported fair or poor health, and the mean number of reported health conditions was 1.9. However, we also examine the plan choices of workers under age 55 as a benchmark.

For 2001, the OPM administrative file contains records on over 370,000 active employees age 55 and under, 12,000 active employees age 65 and older, 28,000 active employees age $60-64$, and 51,000 retirees age $60-64$ who choose self-only coverage. In order to make estimation of the plan choice models more tractable, we take random samples of the current employees age 55 and under, age 60-64, and retirees for our analysis samples. We use all observations for employees age 65 and older. ${ }^{4}$

In the FEHBP, enrollees may choose any local managed care plan if they live or work in a county listed in the plan brochure. These lists typically comprise the counties that are included in the Census Bureau's definition of a Metropolitan Statistical Area (MSA). We, therefore, define the choice set as all plans that operate in the MSA where the person resides, as recorded in the OPM data. Each federal employee or retiree had the choice of eleven national PPO plans in 2001, plus any local plans operating in their market. The local plans are mostly traditional HMO plans, where covered care is restricted to plan providers and facilities. However, there are also several "POS" plans that are similar to HMOs, but allow enrollees to receive care from providers outside of the plan network, but with a higher copayment rate. If a person is not listed as residing in an MSA, but still picks a managed care plan, they are randomly assigned to one of the MSA markets where the plan they choose operates. On average, enrollees had a choice of five local managed care plans, 
with the number of possible managed care plan choices ranging from 0 to 10 plans. About 10 percent of FEHBP enrollees live in an area with no local managed care plan available.

As the government's contribution for a particular plan is fixed from the standpoint of the individual, we will use the individual's share of the annual premium as the relevant premium measure (Feldman et al. 1989). We use a measure of plan actuarial value to control for the overall benefit generosity of the plans. Actuarial value is defined as expected plan benefit spending divided by total expected health care spending (i.e., health plan spending plus out-ofpocket spending) for an actuarially "average" person. The development of actuarial values requires information on the deductibles, copayments, and other key plan parameters (e.g., the structure of mental health benefits). The calculations also require an enrollee population that reflects the FEHBP experience. The actuarial value measure was constructed using FEHBP per capita expenditure levels developed by the author of the Checkbook Guide. This methodology projects out-of-pocket spending for each plan in the program for an actuarially "average" FEHBP enrollee.

In addition to the percentage of total spending that is covered by each plan, consumers may also value the composition of benefits. For example, consumers may prefer a plan with dental coverage to one without dental coverage even if the plans have the same actuarial value. For that reason, we include measures of the composition of benefits for each plan for benefits that vary substantially across FEHBP plans: dental coverage, diabetic supplies, prostheses, hospice care, and chiropractic care. The plans also differ substantially in the structure of their prescription drug benefits. In 2001, most of the plans had formularies that determined the enrollee's out-of-pocket payment for prescription drugs. Typically, a formulary establishes the lowest cost drug to treat a certain condition (which is typically a generic), and has the lowest copayment for that drug. If the patient uses another drug, they will face a larger copayment, or may face the whole cost. We have constructed a variable that measures whether the plan used a drug formulary system to charge different copayments for generics and name-brand drugs.

Several plans offer two different versions of the same plan. The higher benefit plan is labeled the "high option" plan, and the lower benefit plan is called the "standard option." The differences in benefits between these two types of plans may not be completely captured by our benefit measures. For that reason, we include an indicator variable for high option plans that will control for unobserved benefit differences between these types of plans and their standard option counterparts. 
Finally, we only analyze the plan choices of persons who choose selfonly coverage. We do this for three reasons. First, we only have demographic information on the federal employee that is the policyholder of the FEHBP plan. While the federal employee may be comparable with a Medicare enrollee, dependents that are covered by the plan may not be close to Medicare age. In addition, for our comparison group of younger employees, dependent choice decisions for children may be systematically different than they are for adults. Second, we do not observe information about the availability of coverage from a spouse, so we do not observe the complete choice set for family enrollees. Finally, Medicare does not offer family coverage, but is instead explicitly linked to the individual. ${ }^{5}$

\section{RESULTS}

Table 1 shows the mean individual and plan choice set characteristics for each of the four-enrollee populations studied. The retirees and current "pre-Medicare" workers are on average 62 years old, while current Medicare eligible workers are on average over 68 years old. Each of these groups is considerably older than our comparison group of younger employees, who are on average about 43 . Income across the three-employed groups is quite similar at slightly more than $\$ 50,000$, while the retirees have average incomes that are less than half that level. Mean out-of-pocket annual premiums for each group exceed $\$ 870$, with a standard deviation of over $\$ 630$. This is much greater premium variation than exists in the current $\mathrm{M}+\mathrm{C}$ system. Atherly, Dowd, and Feldman (2004) found mean annual out-of-pocket premiums of $\$ 122$, with a standard deviation of $\$ 245$ in the $\mathrm{M}+\mathrm{C}$ program.

Table 2 presents the results of our plan choice regression estimates. The effects of plan out-of-pocket premiums are presented in elasticity form, while the effect of the plan benefits and network structure are presented in terms of willingness to pay. ${ }^{6}$ All groups exhibit responsiveness to out-of-pocket premiums. The comparison group of younger workers has a premium elasticity of -2.43 , which implies that a 1 percent increase in out-of-pocket premiums will lower a plan's market share by 2.43 percent. For the comparison group that is most similar in life circumstance to Medicare retirees, retirees age 60-64, the premium elasticity is significantly lower at -1.97 . The two comparison groups that are actively employed have premium elasticities that are closer to the premium elasticity for young workers $(-2.21)$. These differences with young employees are statistically significant. 
Table 1: Descriptive Statistics for FEHBP Enrollees and Plan Choices

\begin{tabular}{|c|c|c|c|c|}
\hline & $\begin{array}{c}\text { Employees } \\
55 \text { and } \\
\text { under }\end{array}$ & $\begin{array}{l}65 \text { Plus } \\
\text { Employees }\end{array}$ & $\begin{array}{l}\text { Retirees } \\
60-64\end{array}$ & $\begin{array}{c}\text { Employees } \\
60-64\end{array}$ \\
\hline \multicolumn{5}{|l|}{ Person-level variables } \\
\hline Age & $\begin{array}{l}43.13 \\
(8.88)\end{array}$ & $\begin{array}{l}68.40 \\
(3.82)\end{array}$ & $\begin{array}{l}61.79 \\
(1.36)\end{array}$ & $\begin{array}{l}61.59 \\
(1.37)\end{array}$ \\
\hline $\begin{array}{l}\text { Income from federal } \\
\text { employment or retirement }\end{array}$ & $\begin{array}{c}51,081.99 \\
(20,924.14)\end{array}$ & $\begin{array}{c}52,494.07 \\
(24,905.29)\end{array}$ & $\begin{array}{c}25,394.22 \\
(14,082.15)\end{array}$ & $\begin{array}{c}52,635.26 \\
(22,949.64)\end{array}$ \\
\hline $\begin{array}{l}\text { Number of persons } \\
\text { Person-choice-level variables }\end{array}$ & 18,494 & 11,795 & 15,481 & 14,641 \\
\hline Out-of-pocket premium & $\begin{array}{c}871.43 \\
(634.23)\end{array}$ & $\begin{array}{c}889.12 \\
(642.09)\end{array}$ & $\begin{array}{c}880.07 \\
(637.98)\end{array}$ & $\begin{array}{c}881.44 \\
(637.93)\end{array}$ \\
\hline Actuarial value & $\begin{array}{c}0.76 \\
(0.12)\end{array}$ & $\begin{array}{c}0.76 \\
(0.12)\end{array}$ & $\begin{array}{c}0.76 \\
(0.12)\end{array}$ & $\begin{array}{c}0.76 \\
(0.12)\end{array}$ \\
\hline $\mathrm{PPO}=1$ & $\begin{array}{c}0.68 \\
(0.47)\end{array}$ & $\begin{array}{c}0.71 \\
(0.45)\end{array}$ & $\begin{array}{c}0.69 \\
(0.46)\end{array}$ & $\begin{array}{c}0.70 \\
(0.46)\end{array}$ \\
\hline $\mathrm{POS}=1$ & $\begin{array}{c}0.02 \\
(0.15)\end{array}$ & $\begin{array}{c}0.03 \\
(0.16)\end{array}$ & $\begin{array}{l}0.02 \\
(0.14)\end{array}$ & $\begin{array}{c}0.02 \\
(0.15)\end{array}$ \\
\hline High option $=1$ & $\begin{array}{c}0.30 \\
(0.46)\end{array}$ & $\begin{array}{c}0.31 \\
(0.46)\end{array}$ & $\begin{array}{c}0.30 \\
(0.46)\end{array}$ & $\begin{array}{c}0.30 \\
(0.46)\end{array}$ \\
\hline $\mathrm{Rx}$ formulary & $\begin{array}{l}0.87 \\
(0.33)\end{array}$ & $\begin{array}{c}0.87 \\
(0.33)\end{array}$ & $\begin{array}{c}0.87 \\
(0.33)\end{array}$ & $\begin{array}{c}0.87 \\
(0.34)\end{array}$ \\
\hline Dental coverage $=1$ & $\begin{array}{c}0.36 \\
(0.48)\end{array}$ & $\begin{array}{c}0.37 \\
(0.48)\end{array}$ & $\begin{array}{c}0.36 \\
(0.48)\end{array}$ & $\begin{array}{c}0.36 \\
(0.48)\end{array}$ \\
\hline Diabetic supplies $=1$ & $\begin{array}{c}0.93 \\
(0.25)\end{array}$ & $\begin{array}{c}0.94 \\
(0.24)\end{array}$ & $\begin{array}{c}0.93 \\
(0.26)\end{array}$ & $\begin{array}{c}0.93 \\
(0.26)\end{array}$ \\
\hline Prosthesis $=1$ & $\begin{array}{c}0.89 \\
(0.32)\end{array}$ & $\begin{array}{c}0.89 \\
(0.31)\end{array}$ & $\begin{array}{c}0.88 \\
(0.33)\end{array}$ & $\begin{array}{c}0.89 \\
(0.32)\end{array}$ \\
\hline Hospice care $=1$ & $\begin{array}{c}0.39 \\
(0.49)\end{array}$ & $\begin{array}{c}0.40 \\
(0.49)\end{array}$ & $\begin{array}{c}0.41 \\
(0.49)\end{array}$ & $\begin{array}{c}0.40 \\
(0.49)\end{array}$ \\
\hline Chiropractic care $=1$ & $\begin{array}{c}0.23 \\
(0.42)\end{array}$ & $\begin{array}{c}0.24 \\
(0.43)\end{array}$ & $\begin{array}{c}0.23 \\
(0.42)\end{array}$ & $\begin{array}{c}0.23 \\
(0.42)\end{array}$ \\
\hline $\begin{array}{l}\text { Number of person-choice } \\
\text { observations }\end{array}$ & 271,631 & 166,285 & 223,281 & 210,448 \\
\hline
\end{tabular}

Standard errors in parentheses.

PPO, preferred provider organizations; POS, point-of-service; FEHBP, Federal Employees Health Benefits Program.

While all groups show a relatively elastic responsiveness to differences in out-of-pocket premiums, they also show a substantial willingness to pay for certain plan attributes. Younger workers are willing to pay $\$ 2.92$ for each 1 percentage point increase in actuarial value. Each of our comparison groups is willing to pay significantly more than younger workers. An even more striking difference is observed in willingness to pay for plans with open 
Table 2: Premium Elasticity and Willingness to Pay for Plan Attributes

\begin{tabular}{lcccc}
\hline & Employees $\leq 55$ & Employees $\geq 65$ & Retirees 60-64 & Employees 60-64 \\
\hline Premium elasticity & $-2.43^{* * * * *}$ & $-2.21^{* * * *}$ & $-1.97^{* * * * *}$ & $-2.21^{* * * * *}$ \\
& $(0.04)$ & $(0.05)$ & $(0.04)$ & $(0.04)$ \\
Willingness to pay & & & & \\
Actuarial value & $\$ 2.92^{* * * * *}$ & $\$ 3.94^{* * * *}$ & $\$ 3.61^{* * * *}$ & $\$ 3.34^{* * * *}$ \\
& $(0.06)$ & $(0.10)$ & $(0.10)$ & $(0.08)$ \\
PPO & $\$ 504.00^{* * * * *}$ & $\$ 762.24^{* * * *}$ & $\$ 693.00^{* * * *}$ & $\$ 633.08^{* * * *}$ \\
& $(8.17)$ & $(15.83)$ & $(14.17)$ & $(12.53)$ \\
POS & $\$ 114.13^{* * * *}$ & $\$ 216.59^{* * * *}$ & $\$ 176.94^{* * * *}$ & $\$ 170.56^{* * * *}$ \\
& $(14.93)$ & $(23.03)$ & $(25.26)$ & $(22.42)$ \\
High option & $\$ 264.06^{* * * *}$ & $\$ 356.16^{* * * *}$ & $\$ 339.83^{* * * *}$ & $\$ 351.10^{* * * *}$ \\
& $(5.14)$ & $(8.78)$ & $(8.49)$ & $(7.71)$ \\
Rx formulary & $\$ 131.89^{* * * *}$ & $-\$ 223.82^{* * * *}$ & $-\$ 276.80^{* * * *}$ & $-\$ 195.07^{* * * *}$ \\
Dental coverage & $(5.25)$ & $(9.50)$ & $(8.91)$ & $(7.79)$ \\
& $-\$ 1.21$ & $-\$ 6.88$ & $-\$ 73.81^{* * * *}$ & $-\$ 0.91$ \\
Diabetic supplies & $(5.04)$ & $(7.98)$ & $(7.86)$ & $(6.85)$ \\
& $\$ 8.83$ & $\$ 37.38^{* * * *}$ & $\$ 27.93^{* * *}$ & $\$ 54.77^{* * * *}$ \\
Prosthesis & $(6.42)$ & $(12.71)$ & $(11.02)$ & $(10.32)$ \\
& $\$ 44.65^{* * * * *}$ & $\$ 105.19^{* * * *}$ & $\$ 95.67^{* * * *}$ & $\$ 73.49^{* * * *}$ \\
Hospice care & $(5.20)$ & $(9.80)$ & $(8.90)$ & $(7.96)$ \\
Chiropractic care & $-\$ 2.68$ & $-\$ 58.10^{* * * *}$ & $-\$ 4.82$ & $\$ 0.38$ \\
& $(7.77)$ & $(13.30)$ & $(13.43)$ & $(12.19)$ \\
& $\$ 83.40^{* * * *}$ & $\$ 146.18^{* * * *}$ & $\$ 105.44^{* * * *}$ & $\$ 130.63^{* * * *}$ \\
& $(5.08)$ & $(9.09)$ & $(8.21)$ & $(7.68)$ \\
\hline
\end{tabular}

$* * * * * *$ Statistically significant at the 1 and 5 percent level, respectively.

Standard errors in parentheses.

PPO, preferred provider organizations; POS, point-of-service.

provider networks. Young workers are willing to pay slightly more than $\$ 500$ for a PPO plan and approximately $\$ 100$ more for a POS plan than for a closed network HMO. Our comparison groups, however, are willing to pay well over $\$ 600$ for a PPO plan, and current retirees are willing to pay over $\$ 700$. Each older group is also willing to pay substantially more than younger workers for a POS plan.

Each group shows a strong willingness to pay for prescription drug benefits that do not use a formulary to charge different copayments for name brand and generic drugs. Younger employees are willing to pay approximately $\$ 132$ for plans without a formulary, while each of the older groups are willing to pay approximately $\$ 200$ or more.

We also found a positive willingness to pay for various types of ancillary benefits. All groups are willing to pay $\$ 80$ or more for chiropractic services, with the older groups all willing to pay significantly more than young 
employees. This same pattern holds true for diabetic supplies and prosthetics. For dental and hospice services however, the willingness to pay is much lower. Only younger workers show a positive and significant willingness to pay for hospice services, and the willingness to pay for dental services is significantly negative for older workers and retirees.

The large differences in the willingness to pay for open network plans between younger workers and our Medicare comparison groups suggest that there is risk segmentation between open and closed network plans in the FEHBP. Medicare, however, covers an older population than the FEHBP program, so we also examine risk segmentation within each study population to determine the extent of risk segmentation for the older population. We do this by simulating the change in willingness to pay induced by 4 years of aging for each of the groups. These results are presented in Table 3. The willingness to pay for open network plans generally increases with age for all of the groups. However, these changes are generally small. This suggests that there is limited risk segmentation by age within each of the comparison groups, which indicates that segmentation within the Medicare population is likely not as great as selection between our Medicare comparison groups and young employees.

Finally, a key component of the current Medicare reform is the introduction of means testing for part B premiums and prescription drug benefits. While the premiums in the FEHBP do not vary by income, we can use our estimates to simulate how the willingness to pay for open network plans varies by income. We also simulated the willingness to pay for PPO and POS plans at $\$ 20,000$ increments (Table 3). Our results show that there is a substantial and statistically significant change in the how much enrollees are willing to pay for open networks as income increases. For PPO plans the willingness to pay increases by approximately $\$ 100$ for each income increment for each group. For POS plans, however, the willingness to pay declines as income increases. This pattern may simply show that PPO plans are a "normal" good, with demand increasing as income increases, while POS plans are an "inferior" good, with demand decreasing as income increases.

\section{LIMITATIONS}

There are a number of potential limitations to our study. First, the logit model imposes the assumption of the independence of irrelevant alternatives (IIA). If this assumption is not valid, the model will tend to understate the probability that a given choice will be picked relative to the alternatives in the choice set 


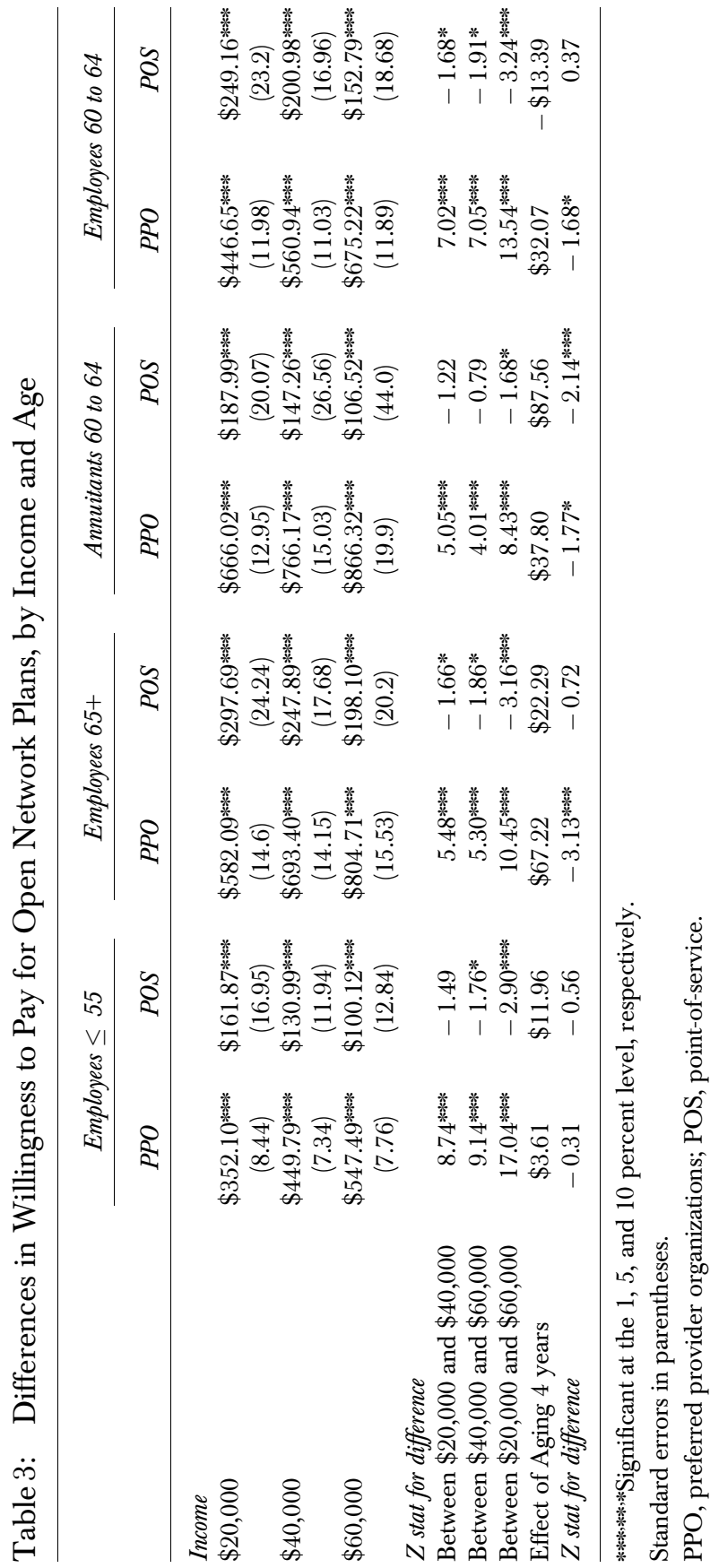


(Amemiya 1985). Therefore, our models may be considered lower bound estimates of the willingness to pay estimates. As our estimation strategy assumes that the error terms are independent, our estimates of the standard errors may be inflated. We attempted to use two alternative models that do not make the IIA assumption: the nested logit model and the random parameters logit model. We estimated nested logit models with the nests defined as PPO or managed care (POS/HMO) plans. However, the model failed tests of IIA within nests, so this alternative did not eliminate the IIA assumption. The random parameters logit models failed to converge. This is likely because of the relatively small number of enrollees in some of the plans.

Second, we do not directly observe health status in our data, which could lead to biased estimates. However, we do observe age and employment status, which are strongly correlated with health status across our different study populations. As we compare plan choice across groups by age and employment status, these proxies for health status are essentially interacted with each of the plan characteristics. We also interact age with the PPO/POS variables within each category, which also controls for the effect of these proxies for health status within categories. Additionally, the conditional logit model "differences out" individual characteristics that are not interacted with plan characteristics, so the regression coefficients would only be biased if the effect of a given plan attribute varies by variation in health status that is not accounted for by age and employment status. Our results are largely consistent in sign and significance across the four groups, suggesting that unobserved health status is not driving the model results. Our ability to observe risk segmentation within the Medicare comparison groups is limited to variation in age. This variation within the Medicare comparison groups is small. Therefore, our results should not be used to make inferences about the "oldest old" in the Medicare population, but are most applicable to recently eligible beneficiaries who will be faced with making choices in the reformed Medicare program over the next several years.

Next, in some situations the plan choices facing each group may vary somewhat. While all FEHBP enrollees in a particular location officially have the same set of choices, the actual choices used in our analysis could differ across the groups. Plans that have very low enrollment (less than 10 persons in each category) are dropped from the analysis before the random samples are drawn, so that if older enrollees have different enrollment patterns than younger enrollees we may select from a different set of plans, potentially creating some random variation in plan choices across the categories because of our random sampling of enrollees, which may miss some plans with low 
enrollment. However, the mean person-choice characteristics in Table 1 show that the average characteristics of the choice sets across the four enrollment categories are quite similar. Older enrollees tend to have a choice of plans with slightly higher out of pocket premiums, but other plan characteristics are very similar across the four-enrollee categories. Therefore, our comparison of premium elasticity across the four groups should not be greatly affected by differences in the choice sets.

\section{CONCLUSIONS}

Recent Medicare reform legislation continues the slow trend toward health plan competition in the Medicare program, featuring enrollee choice of health plans combined with financial incentives in an attempt to induce a cost-conscious choice of health plans. We find that older workers and retirees are similar to younger persons in their response to premiums when choosing a health plan. These older persons show a much stronger preference for opennetwork plans than their younger counterparts, however. This raises the concern that plan choice for the older population may lead to problematic risk segmentation across plans with different network restrictions. A comparison of changes in willingness to pay across older groups that vary by employment status, and within older groups by age, however, show that there appears to be limited selection within the older population. We also find that willingness to pay for open networks varies substantially by income.

The result that older enrollees have a strong preference for open network plans has particularly important implications for choice-based Medicare reform. Older persons clearly show a strong preference for open-network plans. This would suggest that choice-based reform that encourages Medicare beneficiaries to choose closed-network health plans, such as the new Medicare Advantage program, will face a strong consumer preference for open networks. On the other hand, our results show that older persons are also willing to pay a substantial amount to gain access to open networks. Therefore, a reform plan that allows beneficiaries to pay an additional out-of-pocket premium for an open network plan could potentially increase enrollee satisfaction without placing additional financial burdens on the program.

Consumer responsiveness to differences in drug benefits is a major policy concern given the recently enacted Medicare drug benefit. Given the growing share of medical spending devoted to prescription drugs and the recent policy debates on drug prices and insurance coverage, we expected to 
see a strong consumer response to differences in these benefits when choosing a plan. Indeed, we did see a strong consumer response to the structure of drug benefits in our study. Specifically, consumers are willing to pay a substantial amount for equal copays on generic and name brand drugs. The new Medicare drug benefit allows plans to cover only selected drugs within a therapeutic class. Our results suggest that consumers would be willing to pay a substantial amount for an alternative that allowed them to have any drug covered by their prescription benefits.

Finally, a controversial component of the MMA is the introduction of means testing for part $\mathrm{B}$ premiums and prescription drug benefits. While the premiums in the FEHBP do not vary by income, we can use our estimates to simulate how the willingness to pay for open network plans varies by income. The willingness to pay for PPO plans increases with income. This suggest that means testing may be effective in controlling program (but not necessarily beneficiary) costs in Medicare.

\section{ACKNOWLEDGMENTS}

The Robert Wood Johnson Foundation funded this project under its Changes in Health Care Financing and Organization initiative. The authors thank Walton Francis for providing the information on plan benefits. The authors also wish to acknowledge the helpful and carefully considered comments of two anonymous reviewers.

\section{NOTES}

1. Scanlon et al. (1997) have a general review of the health plan choice literature, including studies of the Medicare population. We will focus mainly on subsequent studies in our review.

2. We will refer from this point forward to PPO and POS plans as open network plans, and HMO plans as closed network plans, as the HMO plans all require gatekeepers and require referrals to specialists, even though independent practice association (IPA) HMO plans usually have very large local networks.

3. The total derivative of this expression is taken making two separate assumptions. First, the equation is linear in the variables and second, the variables in the utility function are independent.

4. We drew our random samples in order to have roughly similar sized analysis samples for each group. We sampled 5 percent of current employees age 55 and 
under, 50 percent of current employees age 60-64, and 30 percent of annuitants age 60-64 whose chose self-only coverage.

5. Approximately 36 percent of employees age 55 and under choose single coverage, with those in single coverage being on average one year younger than those in family coverage ( 43.2 versus 44.4 years). For the older populations we study, the family/single split is much more even. Of those choosing single coverage, 45.6 percent are employees 65 and older and 41.7 percent are employees $60-64$ years choose single coverage, with the mean ages between family and single coverage being almost identical ( 68 years old for employees 65 and older, and 62 years old for employees 60-64). Annuitants 60-64 have 45 percent with single coverage, and the mean age is approximately 62 for both single and family coverage. The only substantial observable difference between those choosing single and family coverage is that those in family coverage have higher mean income in all four groups (approximately $\$ 4,000$ for younger employees, $\$ 15,000$ for employees 65 and older, $\$ 11,000$ higher for employees $60-64$, and $\$ 6,000$ for retirees age $60-64)$. We also estimated our models on those enrollees who chose family coverage. The results did not differ substantially from those presented here. These results are available by request from the authors.

6. Full regression results are contained in a separate appendix available from the authors.

\section{REFERENCES}

Amemyia, T. 1985. Advanced Econometrics. Cambridge, MA: Harvard University Press. Atherly, A., B. Dowd, and R. Feldman. 2004. "The Effect of Benefits, Premiums, and Health Risk on Health Plan Choice in the Medicare Program." Health Services Research 39 (4, part 1): 849-66.

Atherly, A., C. Florence, and K. Thorpe. 2005. "Health Plan Switching among Members of the Federal Employees Health Benefits Program." Inquiry 42 (3): 255-65.

Buchmueller, T. 2000. "The Health Plan Choices of Retirees under Managed Competition." Health Services Research 35 (5): 949-76.

Butler, S., and R. Moffit. 1995. "The FEHBP as a Model for a New Medicare Program." Health Affairs 14 (4): 47-61.

Cutler, D., and S. Reber. 1998. "Paying for Health Insurance: The Tradeoff between Competition and Adverse Selection." Quarterly Journal of Economics 113 (2): 43366.

Dowd, B., R. Feldman, and R. Coulam. 2003. "The Effect of Health Plan Characteristics on Medicare+ Choice Enrollment." Health Services Research 38 (1, part 1): 113-35.

Feldman, R., M. Finch, B. Dowd, and S. Cassou. 1989. "The Demand for EmployerBased Health Insurance Plans.” Journal of Human Resources 24 (1): 115-42.

Feldman, R., C. Wisner, B. Dowd, and J. Christianson. 1993. "An Empirical Test of Competition in the Medicare HMO Market." In Competitive Approaches to Health 
Care Reform, edited by R. Arnold, R. Rich, and W. White. Washington, DC: Urban Institute Press.

Florence, C., and K. Thorpe. 2003. "How Does the Employer Contribution for the Federal Employees Health Benefits Program Influence Plan Selection?” Health Affairs 22 (2): 211-8.

HR1. 2003. "Medicare Prescription Drug, Improvement and Modernization Act of 2003, Conference Agreement" [accessed May 11, 2006]. Available at http:// waysandmeans.house.gov/media/pdf/hr1/hrljtexplstate.pdf

O’Sullivan, J., H. Chaikind, S. Tilson, J. Bulanger, and P. Morgan. 2004. "Overview of the Medicare Prescription Drug, Improvement and Modernization Act of 2003,” Congressional Research Service Report for Congress, December 6.

Royalty, A., and N. Salomon. 1999. "Price Elasticities in a Managed Competition Setting." Journal of Human Resources 34 (1): 1-41.

Scanlon, D, M. Chernew, and J. Lave. 1997. "Consumer Health Plan Choice: Current Knowledge and Future Directions.” Annual Review of Public Health 18: 507-28.

Train, K. 2003. Discrete Choice Methods with Simulation. Cambridge: Cambridge University Press. 